\title{
Poder simbólico no reajuste tarifário do transporte metropolitano de passageiros de Porto Alegre na crise de 2004*
}

\author{
Duarte de Souza Rosa Filho**
}

\begin{abstract}
SumÁRio: 1. Introdução; 2. Referencial teórico; 3. Os discursos na crise dos transportes metropolitanos da RMPA em 2004; 4. Poder simbólico no reajuste dos valores das tarifas dos serviços de transporte metropolitano de 2004; 5. Considerações finais.
\end{abstract}

Summary: 1. Introduction; 2. Theoretical framework; 3. Discourses in crises of metropolitan transportation system of RMPA during 2004; 4. Symbolic power in fare readjustment process of metropolitan transit services; 5 . Final remarks.

Palavras-chave: políticas públicas; relações de poder; poder simbólico (Bourdieu); análise crítica do discurso.

KEY WORDs: public policy; power relations; symbolic power (Bourdieu); critical discourse analysis.

Em julho de 2004 ocorreu uma crise no transporte coletivo metropolitano de passageiros da Região Metropolitana de Porto Alegre (RMPA), quando foram queimados ônibus em protestos contra o aumento das tarifas. O presente trabalho visa analisar o exercício do poder simbólico nos discursos pronunciados na elaboração dos estudos do reajuste das tarifas, ou seja, poder da linguagem, como "o poder de constituir o dado pela enunciação, de fazer ver e fazer crer, de confirmar ou de transformar a visão do mundo" (Bourdieu, 2004a:14-15). A fim de potencializar a análise do poder simbólico, foram utilizados os conceitos da análise crítica do discurso (ACD).

\footnotetext{
* Artigo recebido em mar. 2009 e aceito em dez. 2010.

** Docente do Departamento de Administração e do Programa de Pós-Graduação em Ciências Contábeis (PPGCON), Centro de Ciências Jurídicas e Econômicas (CCJE) da Universidade Federal do Espírito Santo (Ufes). Doutor em administração pelo Programa de Pós-Graduação em Administração (PPGA) da Universidade Federal do Rio Grande do Sul (UFRGS), mestre em ciências em transportes pelo Instituto Militar de Engenharia (IME) e engenheiro civil pela Universidade de Brasília (UnB). Endereço: Departamento de Administração, Centro de Ciências Jurídicas e Econômicas (CCJE), Avenida Fernando Ferrari, s/n, Campus Universitário - Goiabeiras - CEP 29060-900, Vitória, ES, Brasil. E-mail: duartesrf@gmail.com.
} 
De acordo com a definição de Fairclough (2001:90), discurso é "o uso de linguagem como forma de prática social". Para Fairclough e colaboradores (2000), baseados nas afirmações de Lemke (1995), a linguagem matemática também é usada para atender a objetivos ideológicos. O trabalho conclui que os discursos pronunciados utilizam a condensação temática para incluir apenas aqueles atores sociais que dispõem de recursos de poder, oriundos do acervo de conhecimentos sobre o processo de produção dos serviços de transportes e do cálculo dos seus custos operacionais, que utilizam formalização matemática.

Symbolic power in Porto Alegre metropolitan transit system fares readjustment process during 2004 crisis

In July 2004 a crisis arose in public transit system in the Porto Alegre Metropolitan Region (RMPA), buses were burned in protests against rising fares. This paper aims to analyze the exercise of symbolic power in the discourses of the studies of fares readjustment, i.e. the use of the power of language as "the power to constitute data through enunciation, to make see and make believe, to confirm or to transform the vision of the world" (BOURDIEU, 2004a:14-15). In order to strength the symbolic power analysis, concepts of critical discourse analysis (CDA) were used. According to the definition of Fairclough (2001:90), speech is "the use of language as a form of social practice". For Fairclough et al. (2000), the mathematical language is also used to serve ideological goals, based on claims of Lemke (1995). The paper concludes that the discourses used the thematic condensation to include only those social actors who have enough power resources from the knowledge about transit services production and about operating costs calculations, which uses mathematical formalization.

\section{Introdução}

O presente trabalho analisa o exercício do poder simbólico, a partir da obra de Pierre Bourdieu (1996, 1998, 2001, 2004a e 2004b), em especial sua definição de poder simbólico, ou seja, poder da linguagem como "o poder de constituir o dado pela enunciação, de fazer ver e fazer crer, de confirmar ou de transformar a visão do mundo e, deste modo, a ação sobre o mundo, portanto o mundo" (Bourdieu, 2004a:14-15), nos discursos pronunciados antes e durante a crise ocorrida nos transportes metropolitanos de passageiros da Região Metropolitana de Porto Alegre (RMPA), em julho e agosto de 2004, quando foram queimados ônibus, em protestos contra o aumento das tarifas do transporte metropolitano, no município de Guaíba. Nesse período, organismos públicos responsáveis pelo setor, a Fundação Estadual de Planejamento Metropolitano e Regional (Metroplan) e a Agência Estadual de Regulação dos Serviços Públicos Delegados do Rio Grande do Sul (Agergs), 
realizaram estudos para justificar os aumentos de preços, baseados em argumentos apresentados pelas empresas operadoras dos serviços do transporte metropolitano de passageiros, representadas pela Federação das Empresas de Transportes Rodoviários do Estado do Rio Grande do Sul (Fetergs) e pela Associação dos Transportadores Intermunicipais Metropolitanos de Passageiros (ATM).

Bourdieu não propôs em sua obra uma metodologia para análise do poder simbólico ou dos discursos. Desta forma, para permitir esta análise, foram incorporados ao presente trabalho os conceitos da análise crítica do discurso (ACD), tendo por base as recomendações de Fairclough (2001) e Fairclough e colaboradores (2000). Fairclough considera que a linguagem matemática também é usada para atender a objetivos ideológicos, baseado nas afirmações de Lemke (1995) sobre a existência de uma estratégia de uso político das formações discursivas, pela transformação dos discursos oriundos das áreas de conhecimentos especializados em discursos sobre política social. De acordo com Fairclough (2000), a partir de Lemke (1995), para identificar a condensação temática nos discursos, as representações matemáticas devem ser transformadas em linguagem a fim de desmascarar as alegações de verdade.

O referencial teórico foi aplicado ao corpora de análise de duas formas: primeiramente, na análise do conjunto de textos de características homogêneas, contido no processo administrativo relativo ao reajuste tarifário ocorrido no ano de 2004 (Processo no 268-13.64/04-8, de 29 de janeiro de 2004, em dois volumes, com 421 páginas). O segundo é constituído pelo conjunto de textos publicados na imprensa local sobre o tema, no período próximo ao respectivo reajuste de tarifas intermunicipais, ou seja, nos meses de julho e agosto de 2004, coletados pela Assessoria de Comunicação Social da Metroplan.

O presente trabalho está estruturado nas seguintes seções: referencial teórico, descrição do contexto de crise e análise do poder simbólico nas disputas discursivas, para permitir estabelecer as considerações finais. O presente trabalho tem origem na tese de doutorado ${ }^{1}$ do autor, da qual resultaram outros artigos, já apresentados em eventos nacionais e internacionais, onde foram incluídos outros autores e outras abordagens teóricas para analisar a referida crise de 2004.

\footnotetext{
${ }^{1}$ Tese submetida para obtenção do título de doutor em administração pelo Programa de PósGraduação em Administração (PPGA) da Universidade Federal do Rio Grande do Sul (UFRGS), sob orientação da profa. dra. Maria Ceci Misoczky.
} 


\section{Referencial teórico}

Bourdieu (2004a) propõe duas sínteses a respeito do poder simbólico, sob a forma de capital simbólico:

a) Na primeira síntese, a língua, como um dos sistemas simbólicos (outros seriam a arte e a religião), como instrumento de conhecimento e de comunicação, é uma estrutura estruturante e estruturada, através da qual é exercido um poder simbólico de construção da realidade "que tende a estabelecer uma ordem gnosiológica: o sentido imediato do mundo (e, em particular, do mundo social)" (Bourdieu, 2004a:9).

b) Na segunda síntese, além de notar "que as relações de comunicação são sempre relações de poder, que dependem do poder material ou simbólico acumulado pelos agentes (ou pelas instituições) envolvidos nestas relações" (Bourdieu, 2004a:11), ele afirma que a língua exerce uma função política, como instrumento de imposição ou legitimação da dominação de uma classe sobre outra, envolvidas numa luta simbólica para impor sua definição do mundo social de acordo com seus interesses e reproduzindo as próprias posições sociais, de forma transfigurada no campo das posições ideológicas.

Bourdieu (2004a:14-15) precisa sua definição de poder simbólico, ou poder da linguagem, como

o poder de constituir o dado pela enunciação, de fazer ver e fazer crer, de confirmar ou de transformar a visão do mundo e, deste modo, a ação sobre o mundo, portanto o mundo; poder quase mágico que permite obter o equivalente daquilo que é obtido pela força (física ou econômica), graças ao efeito específico de mobilização, só se exerce se for reconhecido, quer dizer, ignorado como arbitrário. Isto significa que o poder simbólico não reside nos "sistemas simbólicos" em forma de uma "illocucionary force", mas que define uma relação determinada - e por meio desta - entre os que exercem o poder e os que the estão sujeitos, isto é, na própria estrutura do campo em que se produz e se reproduz a crença. $\mathrm{O}$ que faz o poder das palavras e das palavras de ordem, poder de manter a ordem ou de a subverter, é a crença na legitimidade das palavras e daquele que as pronuncia, crença cuja produção não é da competência das palavras (Bourdieu, 2004a:14-15).

Bourdieu (2004a) afirma que a economia é cada vez mais uma ciência através da qual são dadas respostas políticas a demandas políticas; ao mesmo 
tempo que realiza a proteção das implicações políticas através da utilização de "construções formais, de preferência matemáticas" (Bourdieu, 2001:23). Como exemplo menciona a ligação entre os economistas envolvidos na prática da gestão econômica, através de uma cadeia de legitimidade, com os economistas teóricos puros, que elaboram teoremas matemáticos abstratos com pouca ou nenhuma referência ao mundo econômico real. Essa ligação lhes permite acobertar o caráter de dominação de seus atos (Bourdieu, 2004a). O uso de computadores assume, também, uma função simbólica ostensiva para simbolizar a qualidade científica das profissões (Bourdieu, 2004b).

Bourdieu (2004b:58) afirma que para apreender as condutas que surgem no aspecto político das relações é importante considerar os contextos de conflito, pois neles é mais evidente a ação das organizações do aparato de Estado. Ele também afirma que "o poder constituinte da linguagem (religiosa ou política) e dos esquemas de percepção e de pensamento por ela propiciados fica tanto mais visível em situações de crise: estas situações paradoxais, extraordinárias, requerem um discurso extraordinário..." (Bourdieu, 1996:121).

Tendo em vista a importância do uso da linguagem e a fim de permitir a análise do poder simbólico em relações sociais baseadas na abordagem de Bourdieu, foram incorporados no referencial teórico os conceitos da análise crítica do discurso (ACD). Recorre-se aos trabalhos de Fairclough (2001) e Fairclough e colaboradores (2000). De acordo com a definição de Fairclough (2001:90), discurso é "o uso de linguagem como forma de prática social", portanto tem o sentido de texto e interação. $O$ discurso não é apenas um modo de ação, uma forma de as pessoas agirem sobre o mundo e sobre os outros, mas também é um modo de representação da realidade. Como prática social, existe uma relação dialética entre o discurso e a estrutura social, em que o primeiro é configurado e restringido pela segunda em vários níveis: societário ou em instituições específicas, através de sistemas de classificação, normas e convenções, discursivas ou não. O discurso também é socialmente constitutivo, ao contribuir para a formação de todas as dimensões da estrutura social que, simultaneamente, o moldam e o restringem. O discurso é tanto uma prática de representação do mundo como também de significação do mundo, constituindo-o e construindo-o em significado.

Conforme Fairclough e colaboradores (2000), uma das características do novo capitalismo é o uso da linguagem científica ou matemática para estimar valores e fazer comparações, para medir as políticas públicas e a qualidade dos serviços. Como o capitalismo assume que valores de qualquer natureza podem ser expressos em números, em quantidades de "dinheiro", assume também que quaisquer qualidades, gerais ou particulares, podem ser subsumidas 
na lógica monetária e quantitativa, como árbitro da ordem social. Através dos números, os padrões objetivos de avaliação destes serviços são abstrações muito distantes das realidades vividas, pois resultam de uma ampla variedade de experiências, que passaram por vários tipos de filtros interpretativos.

Para Fairclough e colaboradores (2000), a linguagem matemática também é usada para atender objetivos ideológicos. Ele se baseia nas afirmações de Lemke (1995) sobre a existência de uma estratégia de uso político das formações discursivas, pela transformação dos discursos oriundos das áreas de conhecimentos especializados em discursos sobre política social. A vantagem dessa estratégia tecnocrática reside na apresentação da política como questão de fato que, assim, pode fugir às considerações sobre escolhas de valores e sobre as responsabilidades sociais, morais e políticas de tais escolhas. Essas estratégias, anteriormente restritas ao discurso técnico-científico, com o aumento do poder e da visibilidade da ciência, passaram a ser adotadas nos discursos gerencial e burocrático, que se transformaram em discurso tecnocrático. A opacidade do discurso técnico para o não iniciado permite usar o prestígio e a mística da ciência para obter vantagem no debate político, mas também exige dos tecnocratas a transformação dos discursos técnicos em algo compreensível para uma audiência mais ampla. Esta transformação libera os elementos do discurso técnico de seus padrões contextuais e o redefine de forma a melhor servir aos valores e aos interesses tecnocráticos.

Lemke (1995) diferencia o discurso técnico do tecnocrático. O primeiro possui duas características principais: condensação temática e orientação ao monólogo. Para Lemke (1995), a condensação temática é a característica que permite relatar fatos através da condensação de processos complexos em comunicações resumidas, expressas em linguagem numérica, recorrendo ao status cultural do discurso detido pelo especialista na sociedade, para apresentar-se com neutralidade em relação aos valores e relatar fatos sobre os quais as decisões podem ser tomadas objetivamente. O caráter de ser orientado ao monólogo significa que o discurso é dominado pelo uso da terceira pessoa, na qual o eu e o tu não estão presentes e, portanto, não há espaço para o diálogo.

Por sua vez, o discurso tecnocrático apresenta quatro características identificadas por Lemke (1995):

a) Estratégias baseadas na prática, ou seja, as práticas são recomendadas indiretamente através dos resultados obtidos, afirmados como tendo sido provados, e o modelo da argumentação é baseado nas reivindicações da ciência positivista de identificar causas verdadeiras;

b) Incorpora as condensações do discurso técnico, sem exigir que elas sejam expandidas de forma a que o texto tenha significado para os seus leitores; 
c) São menos monológicos que os textos técnicos;

d) As explicações e os raciocínios são feitos em termos técnicos, compreensíveis apenas para os iniciados, menosprezando as considerações do senso comum, acessíveis a qualquer pessoa.

Para a análise crítica do discurso (ACD), foram adotadas as categorias de análise conceituadas por Fairclough (2001) e Lemke (1995), selecionadas conforme Van Dijk (2000). Em especial, são usadas as características do discurso técnico apresentadas por Lemke (1995): condensação temática e orientação monológica.

O conceito de condensação temática denota a presença de poucos processos de ação direta em comparação com relações abstratas. Os agentes dos processos tendem a não aparecer, os processos são expressos como participantes nas relações, além do uso da voz passiva. Para Lemke (1995), a condensação é a categoria mais geral da qual a nominalização é um caso particular. Os processos são nomeados, reificados e usados em lugar dos agentes humanos, permitindo que toda uma atividade, um processo completo com seus participantes que se realiza em circunstâncias específicas, possa ser entendida simplesmente atribuindo-lhe um nome. As complexas atividades subentendidas podem ser qualificadas e relacionadas a outras de forma enormemente condensadas. A totalidade das atividades e de seu significado é compreendida apenas pelos leitores familiarizados com as formações temáticas intertextuais relevantes, onde estas atividades são explicitamente consideradas. Os discursos que fazem uso desta estratégia dividem o mundo dos leitores potenciais entre os iniciados e os neófitos, em um grau maior do que outros tipos de textos escritos. A extrema confiança na condensação temática é uma das características funcionais mais proeminentes do discurso técnico, que faz uso da matemática como extensão especializada da semântica da linguagem. É possível evidenciar o grau de condensação do discurso observando que o número de itens e relações temáticas não expressadas que são necessários para dar significado àqueles que foram explicitados são em número muito superior aos de outros tipos de discursos (Lemke, 1995).

A orientação monológica se evidencia pela ausência do "eu" e do "tu" no texto, escrito normalmente na terceira pessoa, onde não há espaço para o diálogo, para desacordo ou pontos de vista diferentes. Mesmo o "nós" solidário e inclusivo está ausente; apenas o excludente "nós" representando múltipla autoria é permitido. Desta forma, o mundo do discurso técnico se torna fechado e não admite outro critério de validade fora do seu próprio monólogo. Esta forma de minimizar o uso de intercâmbios interpessoais e a não utilização 
dos recursos dialogais da linguagem são maneiras para reivindicar a posse de neutralidade em relação a valores e pretender ser um relato objetivo dos fatos. Reivindica apresentar fatos que "falam por si mesmos", que não são meramente inferências ou julgamentos. Suas conclusões gerais têm a pretensão de validade universal, nos limites definidos para o assunto. É uma ideologia ${ }^{2}$ positivista, histórica e culturalmente situada, que apresenta os fatos como uma verdade eterna e fora de cogitações humanas (diálogo ou opiniões divergentes), independentemente do agente humano específico com o qual ocorreram os fatos. Lemke (1995) lembra que, em seus primórdios, a ciência utilizava o gênero do diálogo, porém as características do discurso técnico com que a comunidade científica raciocina em termos de suas funções técnicas limitadas também têm sido moldadas historicamente por uma ideologia cultural (positivista) que mantém o papel e a imagem da ciência na sociedade.

Lemke (1995) propõe, também, que se analise o discurso tecnocrático em termos de sua orientação de significado, incluindo todos os aspectos de significado no texto ou discurso pelo qual ele se orienta em direção aos destinatários potenciais, em direção a seu contexto de representação e ao sistema social de vozes de discurso heteroglóssicas ${ }^{3}$ da sua comunidade em geral. Para isto, é preciso verificar como o texto constrói uma posição de avaliação do conteúdo ideacional, e como um valor positivo ou negativo em algum grau é atribuído a um item, relação ou formação temática (o que é bom ou ruim, desejável ou indesejável, adequado ou impróprio, garantido ou duvidoso, normal ou inusual).

Para atender ao objetivo de analisar especificamente a condensação das representações matemáticas nos discursos, Fairclough (2000) apresenta as seguintes orientações, a partir de Lemke (1995):

a) transformar as representações matemáticas em linguagem, desmascarando as alegações de verdade e avaliando-as como qualquer discurso, com atenção especial à ordem do discurso à qual pertence e às suposições sociais, históricas e políticas subjacentes;

\footnotetext{
${ }^{2}$ Para Lemke (1995), ideologia se refere àqueles significados de uso comum, que nós aprendemos, tomados como dados pelo senso comum, mas que dão suporte ao poder de um grupo social para dominar a outros.

${ }^{3}$ Heteroglóssia, para Lemke (1995), é um fenômeno social no qual diferentes partes da comunidade falam com vozes discursivas que assumem posturas específicas de avaliação de sua construção da realidade (significados de representação) em relação à dos outros. A heteroglóssia unifica o processo de estabelecimento de relações entre os destinatários e as audiências com aquelas tomadas de posições de avaliação em direção ao conteúdo ideacional dos nossos próprios discursos e os dos outros.
} 
b) examinar a autoridade culturalmente conferida das medidas, em termos do que é deixado fora da equação matemática, pois diferentes números contam diversas histórias;

c) verificar quais abstrações são usadas em quais situações;

d) de que forma as abstrações são usadas na argumentação, especialmente na mídia e em documentos que relatam os processos de tomada de decisão racional;

e) quais são as maneiras possíveis para resistir a estas avaliações "objetivas";

f) quais argumentos podem ser levantados para resistir ao tecnicismo ou cientificismo dos valores quantitativos, em termos que possam ser escutados no discurso dos tomadores de decisão.

Fairclough (2000) faz estas orientações por entender que é necessário resistir à nova forma do capitalismo globalizado, especialmente à reivindicação neoliberal de que suas políticas são inevitáveis. Seu documento é uma proposta de pesquisa coordenada de ACD sobre o novo capitalismo, com o objetivo de fazer eco aos apelos de Pierre Bourdieu (1998) para que os cientistas sociais assumam suas responsabilidades como intelectuais diante do que esse último apresenta como ameaça à "civilização, associada à existência do serviço público, à da igualdade republicana dos direitos, direito à educação, à saúde, à cultura, à pesquisa, à arte, e, acima de tudo, ao trabalho" (Bourdieu, 1998:37).

Considerando a familiaridade da utilização quotidiana dos transportes coletivos, existem momentos de crise nos períodos dos reajustes dos valores das tarifas. No caso do transporte coletivo metropolitano de passageiros na RMPA, um destes momentos ocorreu em julho de 2004, quando foram queimados ônibus no município de Guaíba em protestos contra o aumento das tarifas do transporte metropolitano. Nesse momento, os organismos públicos realizaram estudos, baseados em argumentos apresentados pelos atores sociais para justificar os aumentos de preços, inclusive sob a forma de uma planilha de cálculo de custos operacionais.

Os textos analisados se referem a este contexto e incluem as manifestações que ocorreram no processo de reajustes tarifários, que tem origem nas solicitações das empresas operadoras que tramitam no aparato de Estado e em suas comissões. A materialidade das informações está contida na cópia do processo administrativo relativo ao reajuste tarifário ocorrido no ano de 2004 
(Processo oㅡ 268-13.64/04-8, de 29 de janeiro de 2004, em dois volumes, com 421 páginas). Incluem, também, as manifestações ocorridas nas notícias publicadas pelos jornais locais da época, coletadas pela Assessoria de Comunicação Social da Metroplan.

Phillips e Hardy (2002) recomendam a utilização apenas de textos produzidos naturalmente, pois são exemplos da linguagem real em uso. Neste sentido, não foram usados questionários ou entrevistas, pois seus resultados não são produzidos de forma natural, ou seja, as respostas são instigadas pelos pesquisadores.

\section{Os discursos na crise dos transportes metropolitanos da RMPA em 2004}

Com a determinação da Metroplan da entrada em vigor das tarifas em 20 de julho de 2004, publicada no Diário Oficial do estado de 17 de julho de 2004, os jornais que circulavam na RMPA começaram a divulgar os novos valores das tarifas para as ligações com origem nos municípios onde circulavam. Nesse período circulavam em Porto Alegre os jornais Correio do Povo, Diário do Comércio, O Sul, Zero Hora e Diário Gaúcho. Pertencentes ao Grupo Editorial Sinos, o Jornal NH circulava em Novo Hamburgo, o Jornal VS, em São Leopoldo e cidades do vale do Rio dos Sinos, e o Diário de Canoas, na cidade de mesmo nome. Em Guaíba circulavam os jornais Gazeta Centro-Sul e Folha Guaibense. O jornal quinzenal Momento Regional circulava em Cachoeirinha e Gravataí.

O contexto de crise começa a ter repercussão na sociedade. Em 26 de julho, de acordo com os jornais, moradores do bairro Santa Rita, de Guaíba, protestaram contra o aumento das tarifas. Durante as manifestações, um grupo dos moradores depredou cinco ônibus e interrompeu duas vezes a via que liga esse município a Porto Alegre (BR-116). À noite, um grupo dos moradores incendiou dois veículos. Policiais da Brigada Militar (BM) e da Polícia Rodoviária Federal (PRF) intervieram na manifestação. O jornal Zero Hora de 27 de julho de 2004 publicou com grande destaque em sua capa a foto colorida de um ônibus em chamas, reproduzida na figura 1. Reportagens com imagens semelhantes foram publicadas, também, nos jornais Correio do Povo, Diário Gaúcho e O Sul, porém com menor destaque que no Zero Hora. 


\section{Figura 1 \\ Ônibus em chamas nas manifestações \\ em Guaíba (26/7/2004)}

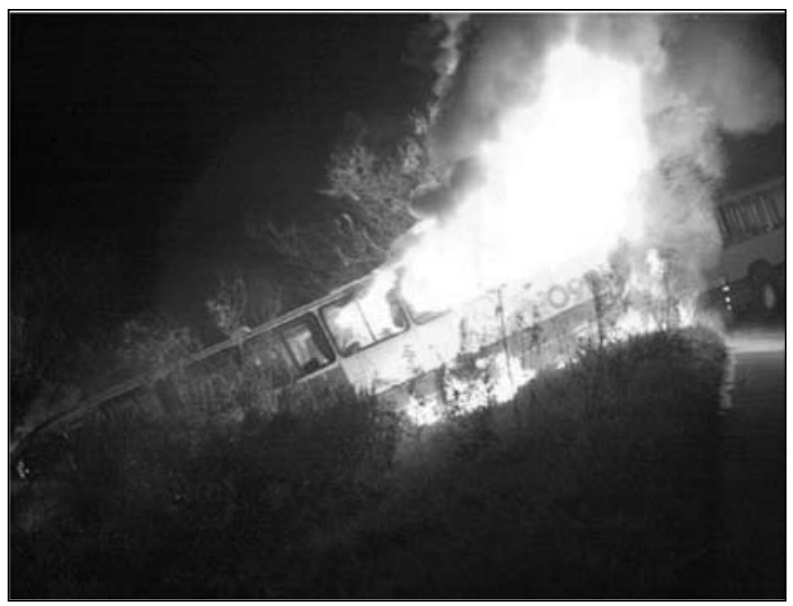

Fonte: VANDALISMO em Guaíba. Zero Hora, Porto Alegre, 27 jul. 2004. p. 1.

Os protestos continuaram nos dias seguintes, com menores depredações, assim como suas repercussões na imprensa local. O Batalhão de Operações Especiais da Brigada Militar é chamado para garantir a segurança dos ônibus em 27 de julho de 2004.

É nesse período que os jornais procuram os usuários dos serviços para escutar suas vozes e que o secretário da Secretaria da Habitação e Desenvolvimento Urbano (Sehadur), em entrevistas, atribuiu os tumultos aos transportadores que atuam em vans e micro-ônibus irregulares, e que estariam perdendo espaço no transporte clandestino. Essa poderia ser a razão para a eclosão de manifestações mais fortes contra o aumento da tarifa ter ocorrido nos bairros Santa Rita e Cohab de Guaíba, de onde parte a maior quantidade de veículos denominados irregulares. Nesse caso, o controle de capital econômico ou cultural por parte dos usuários parece ter sido apoiado com recursos de capital econômico e cultural dos prestadores de serviços por vans.

No dia 28 de julho de 2004 são publicadas notícias, nas páginas quatro e cinco do jornal Zero Hora, tratando da depredação de veículos em manifestações populares contra o aumento da passagem e uma reportagem sobre as viagens em transportes clandestinos. Foi publicada uma foto dos usuários que estariam utilizando microônibus ilegais, sem autorização para operar, reproduzida na figura 2 . 


\section{Figura 2 \\ Foto dos usuários dos transportes ilegais}

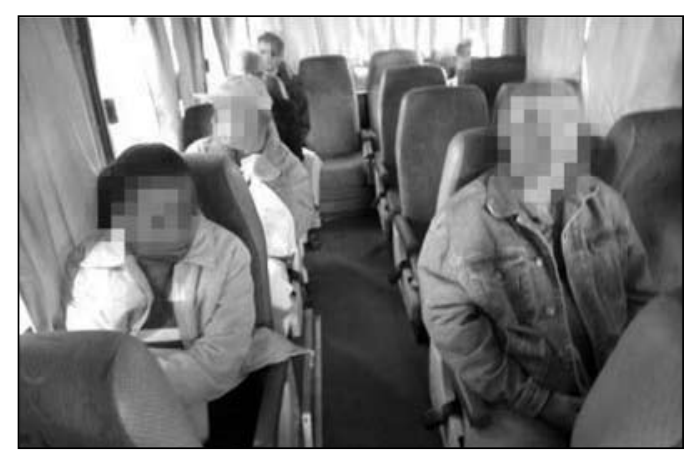

Fonte: DEPREDAÇÃO emperra transporte entre Guaíba e Capital. Zero Hora, Porto Alegre, 28 jul. 2004. p. 5.

Em 29 de julho de 2004 foram noticiadas propostas de redução de tarifas apresentadas pela Metroplan, através da alteração dos itinerários de algumas linhas de forma a evitar o pagamento de pedágio na BR-116, e da implantação de terminal de integração de outras linhas. Nesse mesmo dia, o Zero Hora publicou na página 29 uma reportagem sobre os transportadores clandestinos e sobre uma passeata de moradores dos bairros Santa Rita e Cohab, que contou com o apoio de representantes dos Legislativos estadual e municipal, além de sindicalistas.

A figura 3 mostra a foto publicada do transporte clandestino.

Figura 3

Foto do transporte clandestino

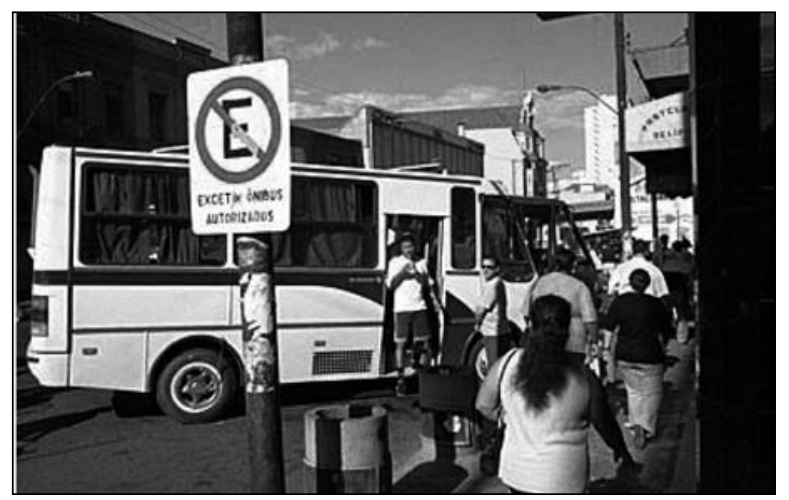

Fonte: CLANDESTINOS dominam bairros. Sem Fiscalização. Zero Hora, Porto Alegre, 29 jul. 2004. Geral, p. 33. 
Nessa data, 29 de julho de 2004, ocorrem novos incidentes como o apedrejamento de ônibus e a tentativa de incendiar outro, contida pela polícia. Dois suspeitos de participar na depredação de um ônibus são detidos pela polícia e um deles é liberado. O secretário estadual dos transportes menciona a elaboração de estudos para a implantação do transporte hidroviário entre Guaíba e Porto Alegre, para desafogar o tráfego na ponte sobre o lago Guaíba.

Foi divulgado pelo jornal O Sul (Porto Alegre, 30 jul. 2004:17) que uma comissão de moradores de Guaíba procurou o Ministério Público para apresentar denúncia de preço abusivo nas passagens dos serviços de transporte coletivo entre Guaíba e Porto Alegre. Nesse dia foram divulgadas notícias, por outros veículos da imprensa, sobre as reuniões mantidas entre a Metroplan, a Prefeitura Municipal de Guaíba e moradores para tratar de alternativas para redução dos valores das tarifas.

Entre os dias 30 de julho e 2 de agosto de 2004 os jornais locais fizeram reportagens sobre a influência do preço das tarifas na obtenção de emprego dos trabalhadores que precisam usar os transportes metropolitanos em seus deslocamentos, devido ao vale-transporte representar um custo mais elevado para os empregadores do que para os que residem próximos dos locais de trabalho.

Foi noticiado, no dia 2 de agosto de 2004, que outra passeata saiu dos bairros Cohab e Santa Rita e chegou ao centro de Guaíba na véspera, domingo, dia 1 o de agosto de 2004, novamente em protesto contra os aumentos nas tarifas. Um dos jornais informou o início da organização de um movimento social na sede local do sindicato dos metalúrgicos, através da realização de uma assembleia de moradores para escolha de representantes de três comissões, de coordenação do movimento, de negociação e técnica para avaliação financeira.

Em 3 de agosto de 2004 é amplamente divulgado o acidente de um ônibus, que fazia o transporte clandestino entre Guaíba e Porto Alegre, que caiu em um valão na BR-290 em Guaíba, com uma foto do veículo, reproduzida na figura 4.

A realização de audiência pública, pela Assembleia Legislativa, para debater a situação do transporte metropolitano, em especial em Guaíba, foi divulgada na imprensa em 4 de agosto de 2004. No dia seguinte, foram noticiadas as propostas dessa audiência e a apreensão de van clandestina pela Metroplan. 


\section{Figura 4 \\ Susto: ônibus acidentado carregava 40 passageiros de Guaíba para a capital}

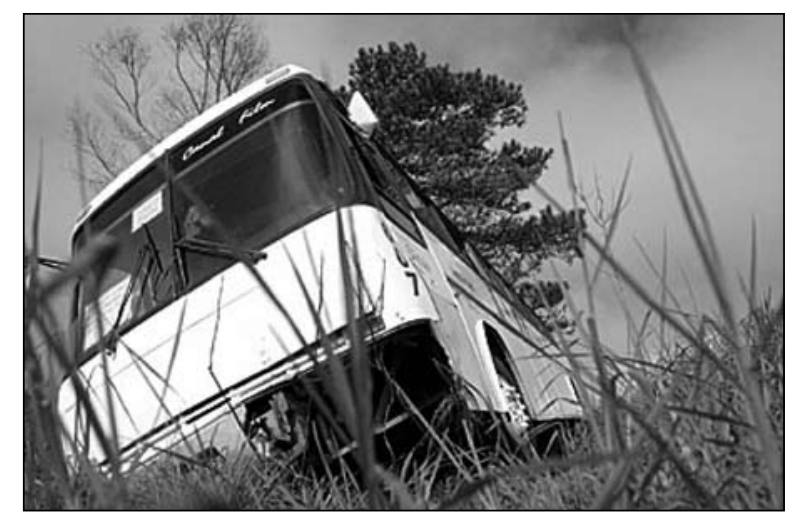

Fonte: ÔNIBUS sem licença sofre acidente ao conduzir moradores de Guaíba. Zero Hora, Porto Alegre, 3 ago. 2004. Transportes, p. 41.

Em 5 de agosto de 2004 foram noticiados novos protestos em Guaíba, desta vez incorporando moradores dos bairros Colina e São Jorge, além daqueles dos bairros Cohab e Santa Rita, quando denominaram a mobilização como Movimento 26 de Julho, data do início das manifestações. Nesse mesmo dia foi noticiada a apreensão pela Metroplan de uma van clandestina que prestava serviços em Guaíba, mostrada na figura 5.

\section{Figura 5}

Apreensão: Topic sem licença foi recolhida a depósito da EPTC

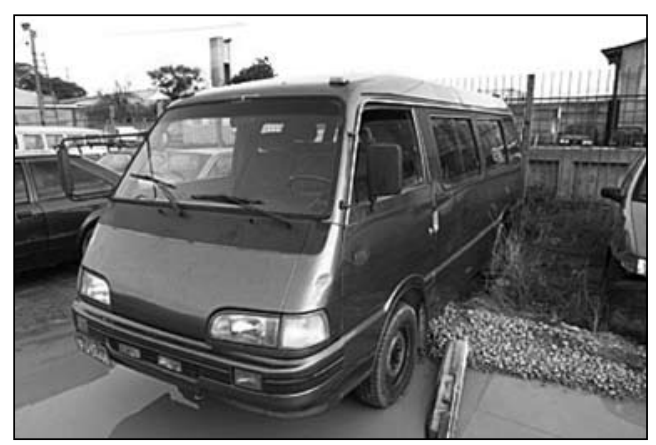

Fonte: METROPLAN apreende van clandestina de Guaíba. Zero Hora, Porto Alegre, 5 ago. 2004. Transportes, p. 38. 
As tarifas de algumas linhas de Guaíba para Porto Alegre foram reduzidas de $\mathrm{R} \$ 2,80$ para $\mathrm{R} \$ 2,60$, aproximadamente $7 \%$, a partir de 6 de agosto de 2004, com a alteração dos itinerários para utilizar a estrada do Conde, paralela à BR-116, a fim de evitar o pagamento do pedágio. Não houve alteração nas tarifas das outras linhas dos serviços de transporte metropolitano.

A partir de meados do mês de setembro de 2004 já não aparecem notícias nos jornais sobre manifestações populares.

Apesar da capacidade de mobilização da imprensa para gerar reportagens e mobilizar outros atores mais dotados de recursos de poder, como representantes do Legislativo ou do Executivo, esse movimento não conseguiu acumular recursos de poder suficientes para tornar-se um ator social e para possibilitar-lhe a participação na produção social do reajuste das tarifas.

O Movimento 26 de Julho só apareceu novamente nos jornais em agosto de 2005, quando ocorreram, outra vez, protestos em Guaíba contra um novo reajuste das tarifas.

No dia 8 de junho de 2006 foi inaugurado o novo Terminal de Integração de Ônibus Nossa Senhora de Fátima, pela Metroplan e a Expresso Rio Guaíba, em parceria com a Prefeitura de Guaíba, dois anos após os incidentes de 2004 (prazo necessário ao projeto e à construção). Esse novo terminal implantou serviços de linhas troncais, com ônibus maiores, e linhas alimentadoras, através de micro-ônibus, para os bairros a oeste do município. A implantação desses serviços diminuiu o custo do transporte, que foi repassado como redução de 16,66\% na tarifa paga pelos moradores dos bairros Pedras Brancas, São Francisco, Bom Fim e Colúmbia City, e de 9,09\% pelos usuários residentes no bairro Jardim dos Lagos.

Com exceção das manifestações de rua, dificilmente os problemas dos usuários são tratados no processo do reajuste das tarifas, como o ocorrido em 2004. Estes eventos tiveram intensa repercussão na imprensa e suscitaram forte mobilização policial para sua repressão.

Os manifestantes não são atores sociais diretos nesse processo e suas vozes obtêm repercussão na imprensa apenas nas manifestações de rua, onde os discursos são feitos em faixas contendo argumentos como "basta do monopólio da Guaíba", "vandalismo é o preço da passagem" e "redução de 20 centavos - piada, rota alternativa - piada, transporte hidroviário - piada" (Desconto..., 2004:37; Moradores..., 2004:9).

Tais ações e argumentos, evidentemente, são insuficientes como capital cultural para habilitá-los a participar no processo. A figura 6 mostra os dizeres das faixas usadas na passeata de $1^{\circ}$ de agosto de 2004. 
Figura 6

Faixas usadas na passeata de $1^{\circ}$ de agosto de 2004

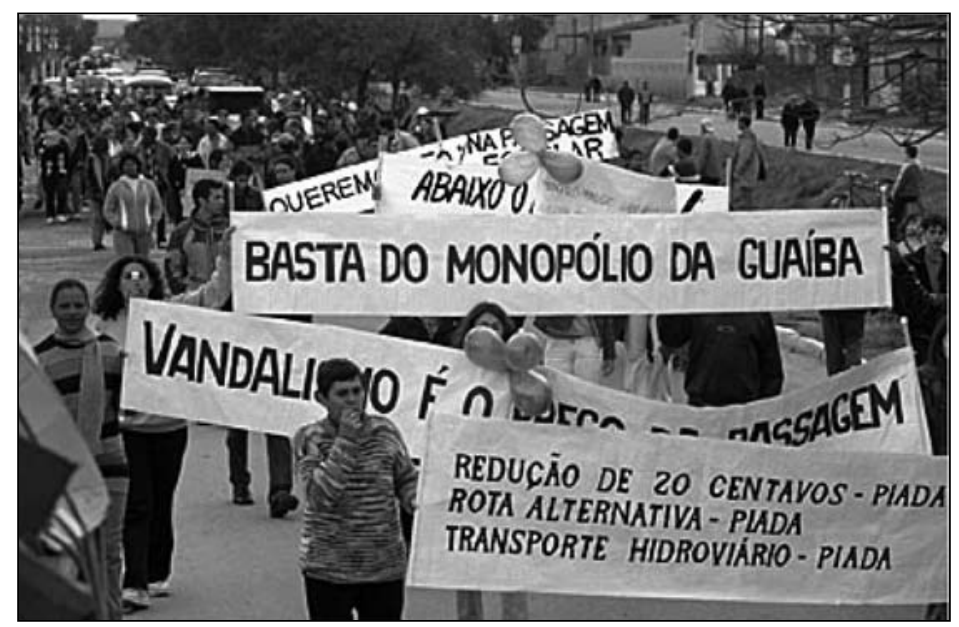

Fonte: PROTESTO pacífico: desta vez não houve tumulto nas manifestações no bairro Santa Rita. ZH Desconto em Guaíba começa a vigorar. Zero Hora, Porto Alegre, 2 ago. 2004. Transporte, p. 37.

A orientação política do governo à época da crise não foi considerada relevante para essa análise porque os diferentes partidos que governaram o estado do Rio Grande do Sul têm mantido a mesma orientação a respeito dos reajustes de tarifas dos transportes coletivos de passageiros da Região Metropolitana, ou seja, de repassar os supostos aumentos de custos das tarifas à população, devidos ao aumento na oferta de serviços e acatando as alegações dos representantes dos empresários de redução na demanda de passageiros, indicada adiante. Desde a Constituição Federal de 1988, o art. 175 estabelece a obrigatoriedade de licitação para concessão dos serviços públicos, na forma de lei posterior (Lei Federal no 8.987/1995, de 13 de fevereiro de 1995).

Através de documentos sigilosos de difícil acesso, produzidos pelo Tribunal de Contas do Estado e pelo Ministério Público Estadual, sabe-se que mais de $90 \%$ dos contratos de concessão do transporte metropolitano estão vencidos e não foram tomadas providências para licitar estes serviços por parte dos governos desde a entrada em vigor dessa lei. Cabe observar que o critério de julgamento das licitações para concessão dos serviços públicos é o de menor valor da tarifa. Situação semelhante ocorre, também, no município de Porto Alegre, onde a totalidade das permissões desses serviços está vencida desde 1996. 
Parecem existir fortes motivos relativos às campanhas político-eleitorais para que essa situação se mantenha, com repercussões nos reajustes tarifários e no posicionamento de representantes do Legislativo e do Executivo nessa questão, tanto no âmbito municipal como estadual.

\section{Poder simbólico no reajuste dos valores das tarifas dos serviços de transporte metropolitano de 2004}

Nos contextos paradoxais e extraordinários das crises ocorre um discurso extraordinário, nas quais os tipos de poder se metamorfoseiam em poder simbólico e são mais perceptíveis (Bourdieu, 1996).

No processo para o estabelecimento dos reajustes nos valores das tarifas dos serviços de transporte metropolitano ocorre uma tensão entre o interesse público e o interesse privado, dado o imperativo do lucro das empresas operadoras privadas. Nesse processo os atores sociais se mobilizam em torno da definição desses interesses, ou seja, pela definição da própria forma de ação do aparato de Estado nos serviços de transporte coletivo metropolitano de passageiros.

As ações dos atores sociais, nesses contextos, se expressam sob a forma de discursos que contêm os argumentos que justificam os reajustes de tarifas e, também, sob a forma matemática na planilha de cálculo tarifário, que usa equações baseadas em conceitos econômicos de custos de produção e de tarifas, calculadas com o auxílio de computadores. Ressalte-se que essa análise é a interpretação crítica dos discursos pronunciados do ponto de vista do autor do presente trabalho.

O exercício do poder simbólico, de produzir o dado pela enunciação, ficou muito evidente no requerimento da Fetergs e da ATM para que a Metroplan procedesse ao reajuste das tarifas dos serviços de transporte metropolitano (Ofício Fetergs no 019/04, de 29 de janeiro de 2007). Ele foi usado para a construção de como seria o processo de produção social desse reajuste, com a definição dos atores sociais que dele participariam ou não. Essas entidades apresentaram vários argumentos jurídicos para excluir a Agergs desse processo, utilizando seus recursos de conhecimentos de forma política para impor sua definição da arena decisória de acordo com seus interesses. Nesse sentido, a Fetergs e a ATM se pronunciam:

Então, poder-se-ia afirmar que a Agência de regulação não teria função nos processos que incidem sobre serviços concedidos no que pertine à definição tarifá- 
ria. Evidentemente que não. A agência é fundamental para o controle e para a fixação de parâmetros que permitam ao poder concedente bem desincumbir-se dos seus misteres legais. Isso não quer dizer que compita à Agência o cálculo de tarifas. Este, por Lei, é do poder concedente. Mais, não pode a agência, a cada processo de reajustamento, modificar os critérios que o Poder concedente utiliza. Deverá, por ser esta sua natureza, informar, com antecedência, quais são os padrões que entende adequados justificando-os (Fundação..., 2004:14).

O recurso ao poder simbólico ficou evidente, também, no requerimento da Fetergs e da ATM para transformar os dados necessários ao cálculo tarifário, que são informados pelas próprias empresas operadoras à Metroplan e foram questionados em processos anteriores, em dados incontestáveis, dotados de legitimidade e de veracidade. Para justificar essa metamorfose, as entidades representativas das empresas prestadoras dos serviços apresentaram argumentos jurídicos baseados em seus recursos de conhecimentos, utilizando-os de forma política para impor seus interesses, bem como anexaram ao requerimento o Ofício SUP no 048/04, de 21 de janeiro de 2004, do diretor superintendente da Metroplan ao presidente da Fetergs, que encaminhou cópias das planilhas das receitas e da quilometragem mensal das empresas operadoras, elaboradas pela Metroplan, com base nos dados fornecidos mensalmente pelas próprias empresas nos boletins de oferta e demanda (BOD).

Nesse processo se constata a metamorfose dos recursos de poder (econômicos, políticos, organizacionais e cognitivos) em poder simbólico, tática coerente com a regra do jogo social em arenas burocráticas.

\subsection{Representações matemáticas do cálculo de tarifa transformadas em texto}

A tarifa é o preço cobrado pela utilização dos serviços de transporte coletivo de passageiros, como função da demanda (quantidade de pessoas que desejam locomover-se), e é calculada pelos custos envolvidos na oferta do serviço (empresas que oferecem lugares ou assentos para aluguel nos veículos que realizam viagens em uma linha). Todas as metodologias de cálculo de custos operacionais e tarifas de transportes coletivos por ônibus usadas no Brasil têm origem nos modelos adotados pelo Conselho Interministerial de Preços (Brasil, 1977).

É possível transformar em texto os símbolos matemáticos, considerando que os custos de produção dos serviços de transporte são calculados de acordo 
com a quilometragem percorrida e se dividem em custos fixos e variáveis. Os custos variáveis são compostos pelas parcelas de combustível, lubrificantes e rodagem (pneus, câmaras de ar, recapagem e protetores). Os custos fixos são compostos pelas parcelas de peças e acessórios, despesas com pessoal (operação, administração e manutenção), despesas de manutenção (peças e acessórios), despesas administrativas (água, luz, telefone, seguros etc.), impostos e taxas. O lucro sobre o capital investido é calculado através da depreciação e da remuneração do capital (frota, instalações e equipamentos), que também são considerados custos fixos; não é prevista a cobrança de lucro extra.

No caso dos custos variáveis, para cada um desses itens e para todas as empresas operadoras dos serviços de um município ou região são feitas médias aritméticas dos consumos ou índices de rendimento dos componentes dos custos variáveis por quilômetro percorrido, os quais são multiplicados pelos preços unitários obtidos no mercado, obtendo-se assim o custo variável total por quilômetro. No caso dos custos fixos, os fatores de rendimento por período de tempo (ano ou mês) são multiplicados pelos respectivos valores (salários, montantes de capital) correspondentes ao mesmo período de tempo; os valores anuais ou mensais, assim obtidos, são divididos pelo número de veículos da frota e pela quilometragem percorrida por ano para obtenção do custo fixo total por quilômetro. A divisão da quilometragem percorrida pela frota por ano é denominada de Percurso Médio Anual (PMA).

A formulação matemática da tarifa resulta da equação em que a receita dos serviços deve ser igual a seus custos para que não haja subsídio governamental, ou seja, a tarifa multiplicada pelo número de passageiros deve ser igual ao custo operacional por quilômetro multiplicado pela quilometragem percorrida. Tem-se, então, que a tarifa é igual ao custo operacional por quilômetro dividido pelo número de passageiros transportados por quilômetro.

Para a tarifa quilométrica, ou seja, aquela em que os usuários pagam conforme a distância que percorrem, o coeficiente tarifário, isto é, a tarifa por quilômetro, é igual ao custo operacional por quilômetro dividido pelo número de passageiros transportados por viagem, multiplicado pela extensão da viagem. A extensão da viagem é a extensão ou o comprimento, em quilômetros, de uma seção ou trecho de uma linha.

Para o cálculo da tarifa de cada linha o coeficiente tarifário é multiplicado pela extensão da linha ou seção. O número de passageiros por viagem e o percurso médio anual, que resultam da especificação da oferta dos serviços, são os mais importantes no cálculo de custos e de tarifas porque refletem as relações entre a oferta e a demanda dos serviços. 
Resulta dessa formulação que a tarifa paga pelos usuários de cada trecho de cada linha não representa o custo efetivo de seu deslocamento no trecho específico, mas é o resultado de uma série de operações aritméticas que envolvem médias de preços e rendimentos de componentes; médias de salários de pessoal; médias de capital investido em veículos, instalações e equipamentos de todas as empresas operadoras; médias em manutenção de veículos e em gastos administrativos. Essas operações aritméticas envolvem, também, médias nos números de veículos das frotas de todas as empresas operadoras, das quilometragens percorridas pelos veículos em um ano (que inclui seu funcionamento durante o dia e seu estacionamento durante a noite), além da média do número de passageiros transportados em cada linha.

O valor da tarifa de cada linha ou trecho é um valor médio obtido pela previsão de receita a ser obtida dos passageiros a fim de cobrir os custos de operação dos serviços. Em outras palavras, a tarifa é uma expressão pseudonumérica originada de uma série de operações matemáticas construídas de acordo com um conjunto de conceitos oriundos da economia, de informações socioeconômicas e de dados estatísticos. ${ }^{4}$

Por limite do número de páginas para a submissão de artigos, não é apresentada e analisada em detalhe a planilha de cálculo da tarifa, em seus diferentes componentes de custo, fatores de consumo ou de utilização, além dos parâmetros operacionais como percurso médio anual e número de passageiros transportados por viagem, e sua forma de obtenção (através dos BODs). Mostrou-se necessário um esforço de síntese para apresentar em linhas gerais as representações matemáticas do cálculo de tarifa transformadas em texto que, para serem detalhadas, exigiriam outro artigo.

\subsection{Análise crítica do discurso do reajuste tarifário}

A condensação temática fica evidente ao longo de todo o processo de produção social do reajuste das tarifas, de forma que as atividades realizadas no complexo processo de produção dos serviços (e seu significado) apenas podem

\footnotetext{
${ }^{4}$ Essa afirmação se baseia em Sant'Anna (1997): os trabalhos científicos no setor transporte dependem, em muitas partes, de modelos de previsão que se apoiam em um conjunto de informações socioeconômicas e dados estatísticos, amostragens e previsões... Não se trata, pois, de um número, quantidade física, mas de uma expressão pseudonumérica de um conceito específico ou de um conjunto deles.
} 
ser compreendidas por aqueles leitores que conhecem esse último processo e, também, o cálculo dos seus custos operacionais.

Os discursos contidos no processo administrativo para o reajuste tarifário usam essa estratégia para dividir o mundo dos interessados entre aqueles que dispõem de recursos de poder oriundos de seu acervo de conhecimentos e os que não os possuem. Dessa forma, ficam excluídos, como possíveis leitores, os usuários dos serviços e a população em geral.

A nominalização ${ }^{5}$ foi amplamente utilizada: o processo complexo de produção dos serviços é apresentado como "o sistema de transporte coletivo de passageiros" (Fundação..., 2004:18); não aparecem agentes humanos no trecho "a frota envelheceu" (Fundação..., 2004:20) ou na justificativa de que "os documentos públicos produzem os indicadores do sistema. Portanto, o Boletim de Oferta e Demanda é o único capaz de traduzir uma realidade aferida publicamente" (Fundação..., 2004:21).

Várias relações abstratas estão presentes, como na definição do "conceito básico de financiamento: custo dividido pelo número de usuários" (Fundação..., 2004:18); isso ocorre, também, na afirmação de que "utilizando o valor que deixou de entrar no sistema" (Fundação..., 2004:20), por ter ocorrido perda de receita, teria sido possível renovar a frota. Outro exemplo de abstração é a afirmação "a perda de receita no período foi da ordem de $\mathrm{R} \$ 5.526 .673,67$ " (Fundação..., 2004:19-20), que teria sido causada pela não aplicação do reajuste na data base de 12 de fevereiro de 2003, embora não tenha sido informada a qual data base se refere.

A condensação temática é, também, evidente no discurso técnico elaborado pela Metroplan, que aplica, intensamente, a matemática nas planilhas de cálculo tarifário (Fundação..., 2004:74-99) como extensão semântica da linguagem. Os números apresentados parecem apresentar fatos que "falam por si mesmos", ou seja, não são meramente cálculos baseados em inferências ou julgamentos dos atores que os elaboram.

O grau de condensação do discurso, em termos do número de itens e das relações temáticas não expressadas, necessárias para dar significado àqueles que foram explicitados, é tão grande que nem os técnicos especializados da Agergs conseguem entendê-los, levando-os a solicitar esclarecimentos sobre

\footnotetext{
${ }^{5}$ Os processos são nomeados, reificados e usados em lugar dos agentes humanos, permitindo que toda uma atividade (um processo completo com seus participantes e que se realiza em circunstâncias específicas) possa ser entendida simplesmente atribuindo-lhe um nome.
} 
o significado de oferta/ano de cada linha e de tarifa de cada linha através do Ofício nº 005/04-DT, de 15 de junho de 2004, nos seguintes termos:

Para melhor desempenhar as atividades de análise do referido expediente requisitamos, com base no inciso VIII do Art. $4^{\circ}$ da Lei n. 10.931/97, o fornecimento das seguintes informações: [...]

3 - o que entende-se por oferta/ano de cada linha?

4 - o que entende-se por tarifa de cada linha?... (Fundação..., 2004:165).

A resposta da Metroplan a essa solicitação, contida no Ofício SUP $n^{\circ}$ 398/04, de 18 de junho de 2004, foi

Ao cumprimentá-lo, vimos por meio deste responder seu ofício n. 005/04 DT, conforme a seguir: [...]

ITEM 3: A oferta/ano representa o número de viagens realizadas multiplicada pelo número de lugares oferecidos pela empresa, que é o dado utilizado para cálculo da receita teórica.

ITEM 4: A tarifa de cada linha é o valor cobrado por passageiros ponta a ponta, desde o ponto inicial (terminal origem) ao ponto final (terminal destino) ou vice-versa, calculada segundo o aproveitamento médio do sistema (Fundação..., 2004:166-167).

Ao longo de todo o processo administrativo observou-se a orientação monológica, caracterizada pela escrita normalmente na terceira pessoa. Esse tipo de orientação monológica pode ser exemplificado pelo pedido contido no requerimento de reajuste tarifário, contido no Of. Fetergs no 019/04, de 29 de janeiro de 2004:

Pelo Exposto, requerem seja concedido reajuste tarifário, considerando-se os dados informativos produzidos e apresentados nas planilhas acima, de modo que a remuneração do sistema seja adequada à realidade presente e, com isso, possa assegurar a qualidade dos serviços que estão sendo prestados, bem como, nos termos da Constituição da República, da Constituição do Estado e da legislação vigente no país, possam os concessionários perceber justa e equilibrada remuneração (Fundação..., 2004:29).

No processo administrativo, nos textos dos diferentes atores sociais, houve espaço para o diálogo e para desacordo em diversos pontos de vista entre a 
Fetergs e a ATM, a Metroplan e a Agergs. Cada um desses atores utilizou seus recursos de poder, principalmente oriundos dos acervos de conhecimentos, para reivindicar neutralidade em relação a valores e pretender apresentar um relato objetivo dos fatos, de forma a não aceitar critérios de validade externos ao monólogo de cada um deles. Pode ser citado como exemplo o relatório do conselheiro relator do processo de reajustamento tarifário no Conselho Estadual de Transporte Metropolitano Coletivo de Passageiros (CETM), de 14 de maio de 2004, onde afirma:

As requerentes abordam inicialmente o conflito de competência entre Agergs e Metroplan, matéria muito bem analisada pela manifestação da assessoria jurídica (doc. Fls. 146/149), que demonstrou inexistir conflito de competência, havendo sim a necessidade de se seguir o procedimento indicado pela lei. Se o representante do Poder Executivo decidir remeter o processo de reajustamento de tarifa homologado pelo CETM à Agergs, para só após a manifestação desta Agência decidir pela aprovação, é faculdade que lhe assiste (Fundação..., 2004:151).

As conclusões gerais de cada ator no processo têm a pretensão de possuir validade universal, nos limites definidos por sua participação no âmbito do processo social de produção do reajuste tarifário. Para mencionar como exemplo, pode-se recorrer ao voto dos conselheiros representantes dos usuários dos serviços de transporte metropolitano, através da Federação Rio-Grandense de Associações Comunitárias e de Moradores de Bairros (Fracab) no CETM ao processo de reajustamento tarifário, datado de 18 de maio de 2004,

A Fracab discorda dos preços utilizados para o cálculo dos custos. Os custos dos insumos são inferiores para os concessionários, como por exemplo, o óleo diesel fixado na planilha a $\mathrm{R} \$ 1,25$.

Discordamos ainda da inclusão na planilha tarifária da taxa da Agergs e Metroplan/SETM, situação esta que retira a imparcialidade na fixação das tarifas. Além disto, somos contrários a inclusão do pedágio, pois o serviço de transporte coletivo deve ser isento de pagamento (Fundação..., 2004, p. 152).

É possível desmascarar as alegações de verdade desse discurso matemático, em especial considerando o que é deixado fora da equação matemática, pois diferentes números contam variadas histórias. Por exemplo, a Fetergs e a ATM afirmam que 
O sistema transportava no ano de 1995, 164,1 milhões de passageiros enquanto que em 2002 este número caiu para 159,5 milhões. Ao mesmo tempo em que o número de passageiros caía, o número de viagens, no mesmo período, crescia de 3,4 milhões para 4,6 milhões. A quilometragem percorrida passava de 84,8 milhões para 120,4 milhões e o índice de ocupação decrescia de 84,6\% para $62,56 \%$. Apesar dos dados negativos, os concessionários, que confiam no sistema, ampliavam a frota disponível de 1.594 veículos em 1995, para 1.894 no ano de 2002 (Fundação..., 2004:18-19).

Assumindo que os dados referentes à queda do número de passageiros sejam corretos, essas entidades não explicam as razões por que isso se deu. Também não apresentam as razões para o aumento da quilometragem percorrida nem justificam o aumento no número de veículos, tendo em vista a redução do índice de ocupação dos lugares oferecidos por parte dos passageiros. Ou seja, não é explicado por que a redução da demanda também não acarretou uma correspondente redução no número de viagens oferecidas, que reduziria a quilometragem percorrida pela frota e, também, a frota de veículos necessários.

\section{Considerações finais}

De acordo com Lemke (1995), existe uma estratégia de uso político das formações discursivas utilizada no discurso técnico-científico: ela transforma os discursos oriundos das áreas de conhecimentos especializados em discursos sobre política social. Se for possível contribuir com o discurso pronunciado neste artigo para a alteração nas políticas de transporte coletivo vigentes na RMPA, considerando as escolhas de valores e as responsabilidades sociais, morais e políticas de tais escolhas, em especial os dos usuários dos serviços, terá valido o esforço da sua elaboração.

Os discursos, como prática social, política e ideológica, utilizam a condensação temática para incluir no processo de produção social do reajuste tarifário apenas aqueles interessados que dispõem de recursos do acervo de conhecimentos sobre o complexo processo de produção dos serviços de transportes e do cálculo dos seus custos operacionais, que utilizam formalização matemática.

Os demais grupos sociais são excluídos do processo do reajuste tarifário por meio do discurso e suas vozes não conseguem ser ouvidas. Seus discursos, apresentados na seção 3 , apesar de toda a repercussão na imprensa, não são 
considerados no processo de reajuste tarifário, por falta de capital cultural e simbólico dos atores sociais representantes dos usuários. Enquanto os atores sociais não aumentam sua dotação de capital cultural, continuam os aumentos nos valores das tarifas.

\section{Referências}

BOURDIEU, Pierre. A economia das trocas linguísticas: o que falar quer dizer. São Paulo: Edusp, 1996.

. Contrafogos: táticas para enfrentar a invasão neoliberal. Rio de Janeiro: Jorge Zahar, 1998.

. Las estructuras sociales de la economía. Buenos Aires: Manantial, 2001.

. O poder simbólico. 7. ed. Rio de Janeiro: Bertrand Brasil, 2004a. 2004b.

. Ofício de sociólogo: metodologia da pesquisa na sociologia. Petrópolis: Vozes,

BRASIL. Conselho Interministerial de Preços (CIP). Roteiro de informações para preenchimento da planilha de custos operacionais. Brasília: CIP, 1977.

CLANDESTINOS dominam bairros. Sem Fiscalização. Zero Hora, Porto Alegre, 29 jul. 2004. Geral, p. 33.

DEPREDAÇÃO emperra transporte entre Guaíba e Capital. Zero Hora, Porto Alegre, 28 jul. 2004. p. 5.

DESCONTO em Guaíba começa a vigorar. Zero Hora, Porto Alegre, 2 ago. 2004. Transporte, p. 37

FAIRCLOUGH, Norman. Discurso e mudança social. Brasília: Editora UnB, 2001.

et al. Language in the new capitalism: a new, revised, and enlarged version of the programmatic document for the LNC network, 2000. Disponível em: <www. cddc.vt.edu/host/lnc/papers/fair_lnc.doc>. Acesso em: 17 set. 2005.

FUNDAÇÃO ESTADUAL DE PLANEJAMENTO METROPOLITANO E REGIONAL (Metroplan). Processo administrativo de reajuste tarifário: Processo oㅡ 268-13.64/04-8. Porto Alegre: Metroplan, 2004.

LEMKE, Jay. Textual politics: discourse and social dynamics. London: Taylor and Francis, 1995.

METROPLAN apreende van clandestina de Guaíba. Zero Hora, Porto Alegre, 5 ago. 2004. Transportes, p. 38. 
MORADORES de Guaíba mantêm mobilização. Correio do Povo, Porto Alegre, 2 ago. 2004. Geral, p. 9.

ÔNIBUS sem licença sofre acidente ao conduzir moradores de Guaíba. Zero Hora, Porto Alegre, 3 ago. 2004. Transportes, p. 41.

PHILLIPS, Nelson; HARDY, Cynthia. Discourse analysis: investigating processes of social construction. Qualitative Research Methods, Thousand Oaks v. 50, 2002.

PROTESTO pacífico: desta vez não houve tumulto nas manifestações no bairro Santa Rita. ZH Desconto em Guaíba começa a vigorar. Zero Hora, Porto Alegre, 2 ago. 2004. Transporte, p. 37.

SANT'ANNA, José Alex. Sobre os dados socioeconômicos e a pesquisa científica. Recife: Fundação Joaquim Nabuco, 1997. Disponível em < www.fundaj.gov.br/docs/text/ jalexs.doc >. Acesso em: 20 set. 2007.

VAN DIJK, Teun. On the analysis of parliamentary debates on immigration. In: REISIGL, M.; WODAK, R. (Ed.). The semiotics of racism: approaches to critical discourse analysis. Vienna: Passagen Verlag, 2000. p. 85-103. Disponível em <www. discursos.org/Vandijk.html>. Acesso em: $1^{\circ}$ fev. 2007.

VANDALISMO em Guaíba. Zero Hora, Porto Alegre, 27 jul. 2004. Primeira página. 